\title{
Alcohol modulation of G-protein-gated inwardly rectifying potassium channels: from binding to therapeutics
}

\author{
Karthik Bodhinathan ${ }^{1}$ and Paul A. Slesinger ${ }^{1,2 *}$ \\ Structural Biology and Peptide Biology Laboratories, The Salk Institute for Biological Studies, La Jolla, CA, USA \\ ${ }^{2}$ Department of Neuroscience, Icahn School of Medicine at Mount Sinai, New York, NY, USA
}

\author{
Edited by: \\ Harley T. Kurata, University of British \\ Columbia, Canada \\ Reviewed by: \\ Brad S. Rothberg, Temple University \\ School of Medicine, USA \\ Nazzareno D'Avanzo, Université de \\ Montréal, Canada \\ Yuichiro Fujiwara, Osaka University, \\ Japan \\ ${ }^{*}$ Correspondence \\ Paul A. Slesinger, Department of \\ Neuroscience, Icahn School of \\ Medicine at Mount Sinai, One \\ Gustave L. Levy Place, New York, \\ NY 10029, USA \\ e-mail:paul.slesinger@mssm.edu
}

Alcohol (ethanol)-induced behaviors may arise from direct interaction of alcohol with discrete protein cavities within brain proteins. Recent structural and biochemical studies have provided new insights into the mechanism of alcohol-dependent activation of $G$ protein-gated inwardly rectifying potassium (GIRK) channels, which regulate neuronal responses in the brain reward circuit. GIRK channels contain an alcohol binding pocket formed at the interface of two adjacent channel subunits. Here, we discuss the physiochemical properties of the alcohol pocket and the roles of $\mathrm{G}$ protein $\beta \gamma$ subunits and membrane phospholipid $\mathrm{PIP}_{2}$ in regulating the alcohol response of GIRK channels. Some of the features of alcohol modulation of GIRK channels may be common to other alcohol-sensitive brain proteins. We discuss the possibility of alcohol-selective therapeutics that block alcohol access to the pocket. Understanding alcohol recognition and modulation of brain proteins is essential for development of therapeutics for alcohol abuse and addiction.

Keywords: addiction, alcohol, G proteins, GIRK, potassium channels, Kir3, $\mathrm{PIP}_{2}$

\section{INTRODUCTION}

Proper nerve cell communication is critical for brain function and depends on a delicate balance of excitatory and inhibitory signaling. Rapid excitatory signaling is mediated by excitatory ionotropic glutamate receptors, such as the NMDA (N-methyl-Daspartate) and AMPA ( $\alpha$-amino-3-hydroxy-5-methyl-4-isoxazole propionic acid) receptors. Inhibitory signaling has fast and slow components, which are mediated by fast inhibitory currents through ionotropic $\mathrm{GABA}_{\mathrm{A}}$-type and glycine receptors and slow inhibitory currents mediated by $\mathrm{G}$ protein-coupled receptors (GPCRs) and G-protein-gated inwardly rectifying potassium (GIRK or Kir3) channels. A large family of GPCRs, including those activated by GABA, DA, glutamate, serotonin, acetylcholine and opioids, directly couple to GIRK channels (Ehrengruber et al., 1997; Luscher et al., 1997; Scanziani, 2000; Wiser et al., 2006; Lujan et al., 2009). In addition, GIRK channels are regulated by interaction with neuronal proteins involved in protein trafficking (Lunn et al., 2007; Balana et al., 2013). GIRK channels allow potassium ions to flow into the cell better than out of the cell, a property referred to as "inward rectification." The small outward current hyperpolarizes the cell's membrane potential, leading to inhibition of neuronal activity. There are four primary neuronal GIRK subunits, GIRK1-GIRK4 (Lesage et al., 1995; Inanobe et al., 1999; Wickman et al., 2000; Luscher and Slesinger, 2010). Alterations in GIRK channel function have been associated with pathophysiology of severe brain disorders like addiction (Hill et al., 2003; Morgan et al., 2003; Labouebe et al., 2007; Kozell et al., 2009), epilepsy (Signorini et al., 1997; Pei et al., 1999; Mazarati et al., 2006), Parkinson's disease and ataxia (Patil et al., 1995; Slesinger et al., 1996; Schein et al., 2005) and Down's syndrome (Siarey et al., 1999; Cooper et al., 2012).

In addition to neurotransmitters that activate GIRK channels via GPCRs, alcohol directly opens GIRK channels at concentrations relevant to human consumption $(18 \mathrm{mM}$ ethanol or $0.08 \%$ blood alcohol level) (Kobayashi et al., 1999; Lewohl et al., 1999; Aryal et al., 2009). Several laboratories have investigated whether ethanol targets GIRK channels in the brain. First, ethanol enhances GIRK currents in VTA neurons (Federici et al., 2009), where they modify the activity of the VTA neural circuit (Michaeli and Yaka, 2010; Padgett et al., 2012). Second, some of analgesic effects of alcohol were found to involve GIRK channels (Ikeda et al., 2002; Blednov et al., 2003). Third, mice lacking GIRK2 channels consume more ethanol and fail to develop conditioned place preference for ethanol when compared to their wild type littermates (Blednov et al., 2001; Hill et al., 2003). Lastly, quantitative trait loci (QTL) mapping identified the GIRK3 subunit in a $0.44 \mathrm{MB}$ region of chromosome 1 that was associated with withdrawal effects following chronic and acute alcohol exposure (Kozell et al., 2009; Ehlers et al., 2010). Taken together, these studies highlight the significance of GIRK channels in the pathophysiology of alcohol consumption and addiction.

Recently, there has been intense interest in the elucidating the molecular mechanism underlying alcohol dependent modulation of brain proteins (Howard et al., 2011b). In this review, we discuss recent developments in understanding the chemical, physical and structural features of alcohol recognition by GIRK channels and other alcohol-sensitive proteins.

\section{ALCOHOL MODULATION OF SIGNALING PATHWAYS, PROTEINS, AND ION CHANNELS}

Ethanol affects multiple signaling pathways in the brain, including dopamine (DA) (Theile et al., 2011; Ben Hamida et al., 2012; Li et al., 2012), serotonin (Engel and Allan, 1999; Sung et al., 2000; McBride et al., 2004; Rodd et al., 2010), opioids (Marinelli et al., 2010; Walker et al., 2011), corticosteroids (Vendruscolo et al., 2012), adenosine (Nam et al., 2013), 
and galanin (Lewis et al., 2004) pathways. Originally, ethanol was hypothesized to interact non-specifically with membrane lipids and consequently, alter the function of integral membrane proteins like ion channels (Harris et al., 2008; Howard et al., 2011b). Indeed, ethanol can modify the activity of some lipid kinases (Tong and Sun, 1996). More recently, it has become clear that ethanol can also modulate ion channels through distinct alcohol binding pockets in the channel protein (Harris et al., 2008; Howard et al., 2011b). Alcohol has been reported to affect several ion channels in the brain. For example, ethanol modulates

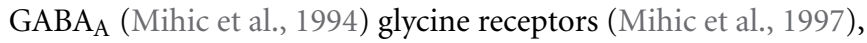
$\mathrm{Ca}^{2+}$-dependent $\mathrm{K}^{+}$channels (Dopico et al., 1998), and acetylcholine receptors (Cardoso et al., 1999), while ethanol inhibits NMDA receptors (Lovinger et al., 1989). In spite of widely documented effects of alcohol on ion channels and receptors, the demonstration of a direct interaction with an ion channel has been elusive. Unlike canonical ligands that saturate a physical binding site, it has been difficult to show saturation of the alcohol binding pocket because the modulatory effects of ethanol occur in the milliMolar range; saturation would not be evident until ethanol reaches hundreds of milliMolar $(>300 \mathrm{mM})$.

Definitive proof for alcohol interacting directly with ion channels can be obtained from high resolution atomic structures. To date, only a few high-resolution X-ray crystallographic structures exist of ion channels with alcohol bound (Aryal et al., 2009; Howard et al., 2011a; Sauguet et al., 2013). These structures provide a snapshot of the location of alcohol pockets in the channel. However, more detailed experiments are needed to relate the function of alcohol modulation to the physical structure. Nevertheless, these crystal structures have revealed certain fundamental properties of the alcohol pockets. The alcohol pockets are relatively hydrophobic composed of hydrophobic amino acid side chains (e.g., F, L, I) and amino acids that form hydrogen bonds with the hydroxyl in alcohol. Similar pockets have been also described in non-ion channel alcohol targets, such as Drosophila odorant-binding protein LUSH (Kruse et al., 2003), protein kinase C epsilon (Hodge et al., 1999; Newton and Ron, 2007) and alcohol dehydrogenase (Plapp, 2010), suggesting some features of alcohol pockets may be conserved in different types of proteins.

\section{STRUCTURAL VIEW OF ALCOHOL POCKET IN GIRK CHANNELS}

GIRK channels assemble into heterotetramers of GIRK1/2, GIRK1/3, GIRK1/4, or GIRK2/3 subunits or in some cases homotetramers of GIRK2 subunits (Figure 1A) (Luscher and Slesinger, 2010). The alcohol pocket in GIRK channels is located at the interface between two adjoining GIRK subunits in the cytoplasmic domains (Figures 1B,C) (Aryal et al., 2009). Originally, the alcohol pocket was first identified in Kir2.1 channels with the alcohol MPD (Pegan et al., 2006; Aryal et al., 2009). The alcohol pocket is formed by three prominent structural elements: $\mathrm{N}$-terminal domain and $\beta \mathrm{D}-\beta \mathrm{E}$ loop from one subunit and the $\beta L-\beta M$ loop from an adjacent subunit (Pegan et al., 2006; Aryal et al., 2009). Through site-directed mutagenesis of amino acids lining the alcohol pocket in GIRK2, Aryal et al. (2009) demonstrated that the alcohol pocket is the site for alcohol-dependent

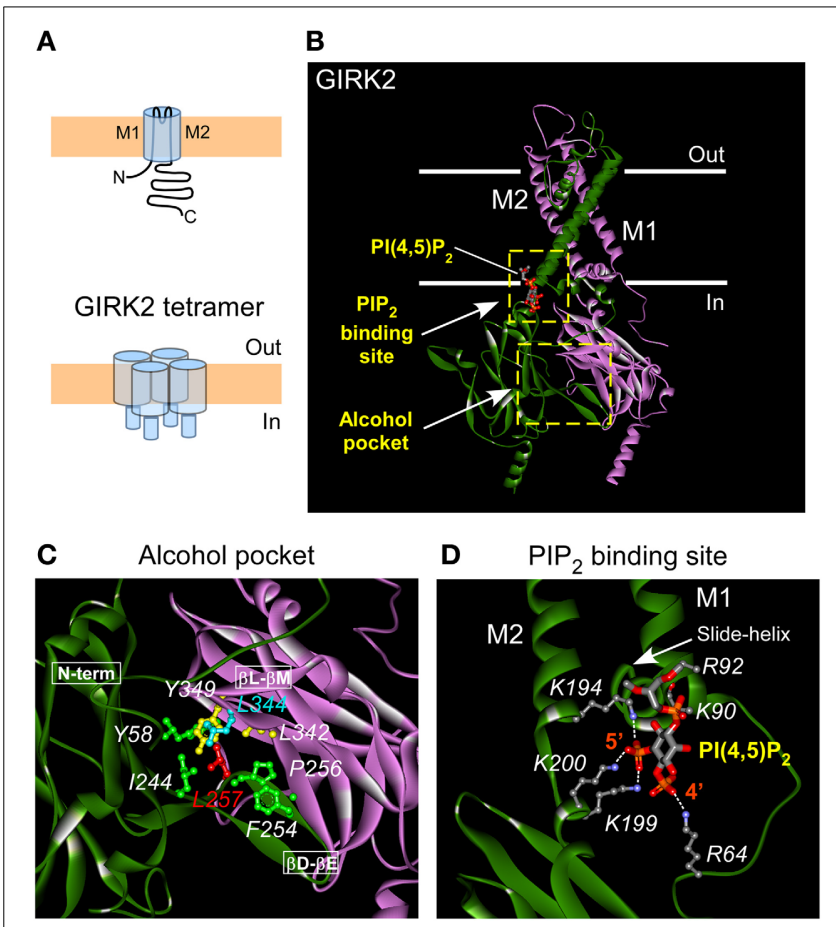

FIGURE 1 | Structural views of alcohol and PIP2 pockets in GIRK2. (A) Schematic of GIRK channel monomer (above) and tetramer (below) depicting the $\mathrm{N}$ and $\mathrm{C}$ terminal regions, and the $\mathrm{M} 1, \mathrm{M} 2$ transmembrane domains. (B) Crystal structure (3SYA) of GIRK2 channel (3.6 A resolution; two of four subunits shown; adapted from Whorton and MacKinnon, 2011) bound to $\mathrm{PI}(4,5) \mathrm{P}_{2} / \mathrm{PIP}_{2}$ (indicated by the arrow). The $\mathrm{PIP}_{2}$ binding site is located at the interface between transmembrane and cytosolic domains of GIRK channel. Solid white lines indicate the approximate boundary of the membrane lipid bilayer. (C) Enlarged view of the alcohol pocket in GIRK2 channel formed by part of N-terminal domain, $\beta D-\beta E$ and $\beta L-\beta M$ loops from two adjacent subunits (Aryal et al., 2009). Amino acids lining the alcohol pocket are indicated, plus critical G $\beta \gamma$ site L344 on the GIRK2 crystal structure (4KFM, Whorton and MacKinnon, 2013). For a view of alcohol bound to the closely related Kir2.1 channel see Aryal et al., 2009. (D) Enlarged view of the $\mathrm{PIP}_{2}$ binding site reveals key residues (shown in ball and stick model) involved in binding PIP $_{2}$ and stabilizing the channel's open state. Also indicated are the major points of electrostatic coordination (white dashed line) between the $4^{\prime}$ and $5^{\prime}$ phosphate of $\mathrm{PIP}_{2}$ molecule and critical residues (R64, K194, K199, K200) in GIRK2 channel (4SYA).

activation of GIRK2 channels. The hydrophobic pocket appears to be conserved within the family of inwardly rectifying potassium channels and across different species (Supplemental Figure S1). The effect of alcohol in the pocket may not produce the same effect on all Kir channels. For example, Kir2 and Kir1 channels are inhibited or unaffected by alcohols, while GIRK channels are activated (Kobayashi et al., 1999; Lewohl et al., 1999). In addition, a L257W mutation in the GIRK alcohol pocket alters alcohol activation but the analogous mutation in Kir2 channels (L245W) produces little effect on alcohol modulation of Kir2 channels. Furthermore, several other mutations to the Kir2 alcohol pocket (specifically F47W, L232W, and L330W) do not alter modulation by alcohols (Aryal et al., 2009). Many of these analogous mutations in GIRK channels render the channel non-functional, however, precluding determination of alcohol sensitivity. 
Recently, the structure of the alcohol pocket in a pentameric ion channel ortholog from the bacterium Gloeobacter violaceus (GLIC) (alcohol sensitized variant F14'A) revealed that GLIC shares many features with the alcohol pocket in GIRK channels (Sauguet et al., 2013). Specifically, the ethanol response of both GIRK and GLIC F14'A channels is altered when the volume of the alcohol pockets are altered with side chains of varying volume (Aryal et al., 2009; Sauguet et al., 2013). Another common feature of the pocket is the placement near a structural or gating transition point. In GIRK channels, the alcohol pocket is located at the interface of two adjacent subunits, whereby the $\beta \mathrm{D}-\beta \mathrm{E}$ and $\beta L-\beta M$ loops move apart from each other during G $\beta \gamma$-dependent activation (Finley et al., 2004; Whorton and MacKinnon, 2011). Similarly, the alcohol pocket in GLIC F14' $\mathrm{A}$ is located in an intersubunit crevice close to the transmembrane domain (M2), which undergoes a conformational rotation during channel activation (Sauguet et al., 2013). Thus, in both channels, alcohol may serve as an allosteric modulator. Lastly, the chemical interactions of alcohol in the pocket involve both hydrophobic and hydrophilic residues. One notable difference is the physical location of the alcohol pocket. In GLIC, the alcohol pocket is located in the transmembrane domains while the pocket in GIRK channels is situated within the cytoplasmic domains. We anticipate that high resolution structures of alcohol in complex different conformational states of the channel in the future will further clarify the molecular mechanism underlying alcohol modulation of ion channels.

\section{CHEMICAL AND PHYSICAL PROPERTIES OF ALCOHOL POCKET THAT DETERMINE LIGAND RECOGNITION}

A remarkable aspect of ethanol's effect on brain function is that this simple chemical compound of only two carbons and a hydroxyl produces long-term behavioral changes in humans. Moreover, ethanol has unusually low potency (mM) and weak selectivity (more than one type of alcohol can achieve similar modulation) for ion channel targets. Recently, Bodhinathan and Slesinger (2013) examined the chemical requirements for activation of GIRK channels using an alcohol-tagging strategy originally described for LGIC channels (Mascia et al., 2000). With a cysteine engineered in the alcohol pocket of GIRK2 (L257C in $\beta \mathrm{D}-\beta \mathrm{E}$ loop), tagging the pocket with both alcohol (hydroxyethyl) and non-alcohol (ethyl or benzyl) like chemical groups led to constitutive channel activation. Thus, the hydroxyl per se was not required for chemical activation of GIRK channels, in contrast to modulation with native alcohols. The hydroxyl may be required for stabilizing native alcohols in the pocket through hydrogen bonding. Tagging GIRK2 channels with a hydroxy-benzyl moiety, however, did not activate the channel, indicating that a small increase in side-chain volume was incompatible with channel activation. Importantly, simply attaching alcohol-like compounds to the $\beta \mathrm{D}-\beta \mathrm{E}$ loop was not sufficient for chemical activation, since tagging S246C situated approximately 7 angstroms from L257 was ineffective at promoting channel activation. Thus, proximity to the pocket and hydrophobicity are key features for chemicaldependent activation of GIRK2 channels through the alcohol pocket.

In addition to hydrophobicity, molecular volume is also a major determinant of sensitivity to alcohol modulation. Based on the estimated volume of different alcohols that activate GIRK channels and the volume of amino acid side-chains that line the pocket, the GIRK alcohol pocket is estimated to be $\sim 312 \AA^{3}$ (Bodhinathan and Slesinger, 2013). This volume could optimally accommodate two or three ethanol molecules. By comparison, the alcohol pocket of the GLIC F14'A channel has been estimated to be $\sim 335 \AA^{3}$ (Howard et al., 2011a), but contained only one bromo-ethanol compound. Future high-resolution crystal structures of alcohol bound to the GIRK alcohol pocket will be needed to determine the precise stoichiometry of ethanol and its stereospecific arrangement within the pocket.

In summary, the emerging view of the physiochemical properties of the alcohol pocket suggests that ligand occupancy and modulation through these pockets are determined by the hydrophobicity and volume. In addition, the location of the alcohol pockets at the interface of channel subunits (e.g., GIRK and GLIC) reveals a fundamental topographical design that makes it accessible to alcohol and facilitates intersubunit conformational changes that underlie channel opening. These features enable the alcohol pockets to act as critical modulatory sites for these channels.

\section{CONVERGENCE OF GIRK CHANNEL REGULATORS WITH ALCOHOL-DEPENDENT ACTIVATION}

The primary pathway for GIRK channel activation occurs through stimulation of GPCRs that couple to pertussis-toxin sensitive $\mathrm{G}$ proteins $(\mathrm{Gi} / \mathrm{o})$, which in turn directly activate GIRK channel via $G$ protein $G \beta \gamma$ subunits (Logothetis et al., 1987; Reuveny et al., 1994; Wickman et al., 1994; Huang et al., 1995; Kunkel and Peralta, 1995). Mutagenesis and biochemical G $\beta \gamma$ binding experiments implicated several regions in the cytoplasmic domains involved in G $\beta \gamma$ activation, with a particular emphasis on the involvement of a Leucine in the $\beta \mathrm{L}-\beta \mathrm{M}$ loop (L344 in GIRK2, L333 in GIRK1) (Huang et al., 1995, 1997; He et al., 1999; Ivanina et al., 2003; Finley et al., 2004). Whorton and MacKinnon (2013) recently solved the crystal structure of a GIRK2-G $\beta \gamma$ complex and confirmed that L344 interacts directly with the G $\beta$ subunit. Leu55 on G $\beta$ forms hydrogen bonds with L344 as well as with several other sites near the alcohol pocket (F254, P256, L342, and Y349). Similarly, taking a computational approach, Mahajan et al. (2013) recently pinpointed an interaction between L55 in G $\beta$ and L333 in GIRK1, demonstrating that a disulfide can form between L55C and L333C and lead to sustained activation (Mahajan et al., 2013). According to this model, G $\beta \gamma$ binds to the GIRK channel at the cleft formed by the $\beta \mathrm{D}-\beta \mathrm{E}$ and $\beta \mathrm{L}-\beta \mathrm{M}$ loop from adjacent GIRK subunits, stabilizing the open conformation of the $\mathrm{G}$ loop gate that precedes channel opening and ion permeation. Remarkably, the region of $G \beta \gamma$ interaction overlaps completely with the alcohol pocket (Bodhinathan and Slesinger, 2013). GIRK channels are also regulated (but not activated) by G $\alpha$ subunits (Ivanina et al., 2004; Clancy et al., 2005; Rubinstein et al., 2007). Interestingly, NMR experiments suggest a different region of the cytoplasmic domain is involved (Mase et al., 2012).

Previous studies suggested that alcohol activation occurs independently from receptor-dependent activation (Kobayashi et al., 1999; Lewohl et al., 1999). Using an alcohol tagging strategy with GIRK2, Bodhinathan and Slesinger (2013) found that MTS-HE 
modification of the G $\beta \gamma$ L344 site reduced basal GIRK2 current, while modification of L257 increased the basal GIRK2 current. Furthermore, varying the levels of G $\beta \gamma$ subunits consistently altered the rate of MTS-HE-dependent inhibition of L344C but had little effect on modification of L257C. Thus, in spite of the considerable overlap in the alcohol and $G \beta \gamma$ binding sites, activation by MTS-HE does not seem to be influenced by alterations in the G $\beta \gamma$ levels. Taken together, these results support a model where association between G $\beta \gamma$ and GIRK2 L344 in the $\beta \mathrm{L}-\beta \mathrm{M}$ loop, similar to L333 in GIRK1 (Mahajan et al., 2013), precedes alcohol-mediated activation in the pocket.

A regulator that is common to all inwardly rectifying $\mathrm{K}^{+}$channels is the membrane-bound phospholipid-phosphatidylinositol 4,5-bisphosphate (PIP 2 ) (Huang et al., 1998; Zhang et al., 1999). $\mathrm{PIP}_{2}$ is required for the constitutive basal activity of inward rectifiers like Kir1, Kir2 and Kir3 (GIRK) channels. PIP $_{2}$ association also underlies agonist-dependent activation of GIRK channels (Huang et al., 1998; Zhang et al., 1999; Xiao et al., 2003). An examination of the relative affinity for $\mathrm{PIP}_{2}$ indicated that GIRK channels interact weakly with $\mathrm{PIP}_{2}$ and G $\beta \gamma$-dependent activation increases the affinity for PIP $_{2}$ (Huang et al., 1998; Zhang et al., 1999). High-resolution structural studies indicate that the $5^{\prime}$ phosphate in $\mathrm{PIP}_{2}$ is critical for binding to GIRK at the membrane-cytosol interface (Figure 1D) (Whorton and MacKinnon, 2011). Like G $\beta \gamma$-dependent activation, alcoholdependent activation also depends on $\mathrm{PIP}_{2}$ interaction with the channel. Alcohol fails to activate GIRK channel in cells where $\mathrm{PIP}_{2}$ levels are depleted using a voltage-activated phosphatase (Dr-VSP) that removes the $5^{\prime}$ phosphate (Bodhinathan and Slesinger, 2013). Moreover, presence of alcohol in the pocket slows down that rate of $\mathrm{PIP}_{2}$ dissociation from the channel, suggesting an increase the relative affinity between $\mathrm{PIP}_{2}$ and the GIRK channel. Thus, structural changes in the $\mathrm{PIP}_{2}$ binding interface in GIRK channels is a critical gating step for two distinct pathways for activating GIRK channels, slower G $\beta \gamma$-dependent activation and rapid alcohol-dependent activation.

Alcohol may facilitate a "sliding" movement of the two adjacent GIRK subunits, increasing the affinity for $\mathrm{PIP}_{2}$, and inducing movement of the channel's $G$ loop and transmembrane gates to allow ion permeation (Pegan et al., 2005; Whorton and MacKinnon, 2011, 2013; Mahajan et al., 2013). Increasing the hydrophobicity of the pocket, either by chemical-tagging with an alcohol-like short-chain molecule or by native alcohol itself, lowers the free energy barrier $(\Delta G)$ for channel opening (Figure 2), similar to alcohol-sensitive ligand-gated ion channels (LGICs) (Mascia et al., 2000). Alcohol binding to the pocket may produce weak van der Waal and hydrogen bond interactions with several residues in the $\beta \mathrm{D}-\beta \mathrm{E}$ and $\beta \mathrm{L}-\beta \mathrm{M}$ loops that line the pocket of GIRK channels and stabilize an open state, through increasing the $\mathrm{PIP}_{2}$-GIRK affinity. In the alcohol-sensitized GLIC, the B-factor is decreased in the presence of ethanol, suggesting that alcohol also stabilizes an open state (Sauguet et al., 2013). An attractive feature of an allosteric model for gating is that it is compatible with (1). low affinity of GIRK channels for alcohol, (2). low binding energy associated with alcohol-dependent activation of GIRK, and (3). apparent lack of chemical specificity for alcohols

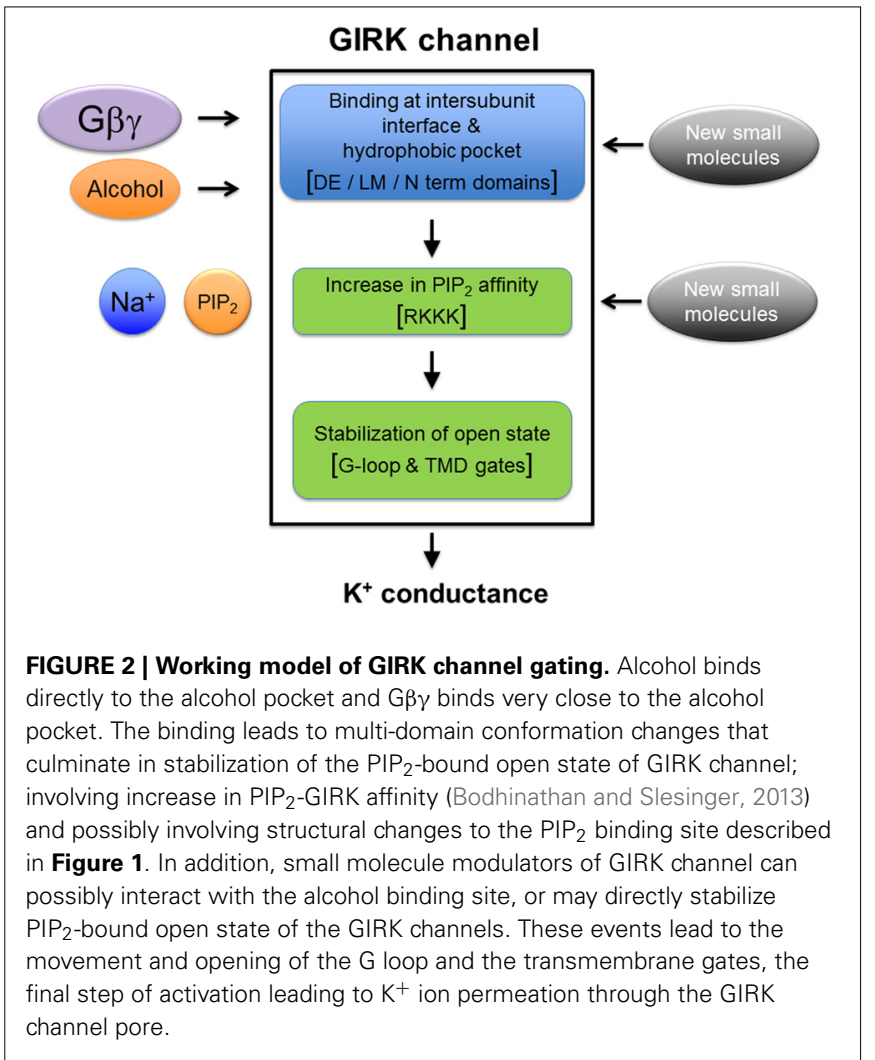

that can be accommodated within the GIRK alcohol pocket (Harris et al., 2008). How it is that alcohol- and G $\beta \gamma$-dependent activation mechanisms are independent yet have partially overlapping binding sites remains an important question for future studies.

In fact, the involvement of changes in affinity between $\mathrm{PIP}_{2}$ and GIRK channels is emerging as a common theme in the activation of GIRK channels by alcohol (Bodhinathan and Slesinger, 2013), G $\beta \gamma$ (Huang et al., 1998; Whorton and MacKinnon, 2013) and $\mathrm{Na}^{+}$(Ho and Murrell-Lagnado, 1999; Petit-Jacques et al., 1999; Inanobe et al., 2010; Whorton and MacKinnon, 2011). Based on this model of convergence at the $\mathrm{PIP}_{2}$ binding site for these distinct activators, we can highlight certain unanswered points. Alcohol binding at the cytoplasmic domain could structurally re-arrange the $\mathrm{PIP}_{2}$ binding site in a manner that increases the physical retention of $\mathrm{PIP}_{2}$ at this site (Xiao et al., 2003; Whorton and MacKinnon, 2011). One question that remains unanswered is whether the physical rearrangements in the alcohol pocket are inextricably linked to changes in $\mathrm{PIP}_{2}$ binding. Based on the current results, it is unlikely a GIRK mutant will be identified that is deficient in $\mathrm{PIP}_{2}$ binding but has normal alcohol activation. A related question is whether a point mutation will be identified that creates an alcohol resistant GIRK channel that retains $G \beta \gamma$ activation. Lastly, it is unknown what determines the subtle differences in alcohol activation of GIRK channels composed of different subunits (Kobayashi et al., 1999; Lewohl et al., 1999). Thus, any therapeutic strategy to treat alcohol addiction and abuse will need to take into account these remaining questions. 


\section{CLINICAL IMPLICATIONS}

Currently, there are no adequate treatments for alcohol dependence and addiction. Traditional approaches to treat alcohol abuse problems have targeted the stress and anxiety pathways in the brain to ameliorate alcohol craving and manage painful withdrawal symptoms (Silberman et al., 2009; Zorrilla and Koob, 2010; Pastor et al., 2011). Recently, several therapeutic strategies are currently approved or in clinical trials for treating alcoholism. In 2012, Baclofen was approved as treatment for alcoholism by the French agency AFSSAPS. In U.S., based on recent advances in clinical research (Ameisen, 2005; Addolorato et al., 2011), NIAAA is finishing Phase-2 clinical trials testing Baclofen as treatment for alcoholism (ClinicalTrials.gov Identifier: NCT01751386). Baclofen is an agonist for $\mathrm{GABA}_{B}$ receptors, which activate GIRK channels, inhibit voltage-gated calcium channels, and alter cAMP levels. However, Baclofen, originally developed to treat muscular spasticity (Penn and Kroin, 1985), produces numerous undesirable side-effects like headache, sleepiness, exhaustion, vertigo, nausea, and insomnia (Addolorato et al., 2011).

Another strategy for treating alcoholism could be to antagonize the direct action of alcohol in the brain through alcoholselective therapeutics. Understanding the chemical nature of the GIRK alcohol pocket has revealed unique chemical rules that are associated with channel activation. The chemical rules of hydrophobicity and size of the ligand occupying the pocket, have significant implications for the development of chemical therapeutics that can occupy the pocket and selectively prevent alcohol access to GIRK channels. It may be possible to design smart chemicals that do not engage the channel activation mechanism through the pocket but selectively block access to alcohol. Interestingly, numerous synthetic ligands have been reported to modulate GIRK channel function, including antidepressants (Kobayashi et al., 2004, 2011; Hamasaki et al., 2013), antipsychotics (Kobayashi et al., 2000; Heusler et al., 2011), and anesthetics (Slesinger, 2001; Yamakura et al., 2001; Zhou et al., 2001; Styer et al., 2010). Recently, a small compound was described that selectively activates heterotetramers containing the GIRK1 subunit and exhibits anti-epileptic properties (Kaufmann et al., 2013). It is not known where this compound acts, but it offers an opportunity to discover possible antagonists for ethanol-dependent activation.

\section{FUTURE CHALLENGES}

To fully describe the universal properties of alcohol pockets, more high resolution crystal structures of ion channels bound to alcohol are needed. Future studies exploring the link between changes in alcohol pocket chemistry and ion channel structure will be helpful for developing novel anti-addiction therapeutics that carry minimal dependency and high degree of selectivity. Whether there are differences in ethanol sensitivity amongst different GIRK subunits is poorly understood. Of particular note, GIRK2/3 channels are exclusively expressed in VTA DA neurons (Cruz et al., 2004) and exhibit reduced sensitivity to G $\beta \gamma$ (Jelacic et al., 2000).

Although these studies implicate the GIRK channel in alcohol binding, it remains unknown whether altering the GIRK channel composition or alcohol pocket chemistry will yield "alcoholresistant" mutants. For example, future studies will need to identify mutations with the alcohol pocket of GIRK channels from human or closely related rat and mouse GIRK channels, which exhibit alcohol-deficient response but normal $G$ protein gating. Such GIRK mutants can be used to create novel knock-in animals that do not develop alcohol-related behavioral changes or alcohol addiction. Furthermore, it is predicted that such knock-in animals will have fewer phenotypic side effects due to unaltered $G$ protein response. On the other hand, altering the alcohol pocket chemistry in GIRK channels can enhance ethanol response, which would be an unwanted side-effect. This finding highlights the intricate chemical and physical nature of the alcohol pocket in GIRK channel.

\section{AUTHOR CONTRIBUTIONS}

Karthik Bodhinathan and Paul A. Slesinger co-wrote the manuscript.

\section{ACKNOWLEDGMENTS}

This work was supported by the American Heart Association Postdoctoral Fellowship (12POST9830002 to Karthik Bodhinathan), the 2011-Pioneer Fund Postdoctoral Scholarship (to Karthik Bodhinathan), and grants from NIAAA (AA018734) and NIDA (DA019022) to Paul A. Slesinger.

\section{SUPPLEMENTARY MATERIAL}

The Supplementary Material for this article can be found online at: http://www.frontiersin.org/journal/10.3389/fphys.2014. 00076/abstract

\section{Supplemental Figure $\mathbf{S} 1$ | Conservation of amino acids in alcohol pocket} across species. Clustal Omega (EMBL-EBI) alignment of GIRK2 (Kir3.2/KCNJ6) sequences from different species reveals a high degree of conservation in the domains forming the alcohol pocket: $\mathrm{N}$-terminal domain (pink), $\beta$ D- $\beta$ E loop (green) and $\beta L-\beta M$ loop (blue). Leucine 257 (bold), which plays a critical role in alcohol activation, is conserved across multiple species. The respective NCBI sequence ID is also indicated.

\section{REFERENCES}

Addolorato, G., Leggio, L., Ferrulli, A., Cardone, S., Bedogni, G., Caputo, F., et al. (2011). Dose-response effect of baclofen in reducing daily alcohol intake in alcohol dependence: secondary analysis of a randomized, double-blind, placebo-controlled trial. Alcohol Alcohol. 46, 312-317. doi: 10.1093/alcalc/agr017

Ameisen, O. (2005). Complete and prolonged suppression of symptoms and consequences of alcohol-dependence using high-dose baclofen: a self-case report of a physician. Alcohol Alcohol. 40, 147-150. doi: 10.1093/alcalc/agh130

Aryal, P., Dvir, H., Choe, S., and Slesinger, P. A. (2009). A discrete alcohol pocket involved in GIRK channel activation. Nat. Neurosci. 12, 988-995. doi: 10.1038/nn.2358

Balana, B., Bahima, L., Bodhinathan, K., Taura, J. J., Taylor, N. M., Nettleton, M. Y., et al. (2013). Ras-association domain of sorting Nexin 27 is critical for regulating expression of GIRK potassium channels. PLOS ONE 8:e59800. doi: 10.1371/journal.pone.0059800

Ben Hamida, S., Neasta, J., Lasek, A. W., Kharazia, V., Zou, M., Carnicella, S., et al. (2012). The small G protein H-Ras in the mesolimbic system is a molecular gateway to alcohol-seeking and excessive drinking behaviors. J. Neurosci. 32, 15849-15858. doi: 10.1523/JNEUROSCI.2846-12.2012

Blednov, Y. A., Stoffel, M., Alva, H., and Harris, R. A. (2003). A pervasive mechanism for analgesia: activation of GIRK2 channels. Proc. Natl. Acad. Sci. U.S.A. 100, 277-282. doi: 10.1073/pnas.012682399 
Blednov, Y. A., Stoffel, M., Chang, S. R., and Harris, R. A. (2001). Potassium channels as targets for ethanol: studies of G-protein-coupled inwardly rectifying potassium channel 2 (GIRK2) null mutant mice. J. Pharmacol. Exp. Ther. 298, 521-530.

Bodhinathan, K., and Slesinger, P. A. (2013). Molecular mechanism underlying ethanol activation of G-protein-gated inwardly rectifying potassium channels. Proc. Natl. Acad. Sci. U.S.A. 110, 18309-18314. doi: 10.1073/pnas.1311 406110

Cardoso, R. A., Brozowski, S. J., Chavez-Noriega, L. E., Harpold, M., Valenzuela, C. F., and Harris, R. A. (1999). Effects of ethanol on recombinant human neuronal nicotinic acetylcholine receptors expressed in Xenopus oocytes. J. Pharmacol. Exp. Ther. 289, 774-780.

Clancy, S. M., Fowler, C. E., Finley, M., Suen, K. F., Arrabit, C., Berton, F., et al. (2005). Pertussis-toxin-sensitive Galpha subunits selectively bind to C-terminal domain of neuronal GIRK channels: evidence for a heterotrimeric G-protein-channel complex. Mol. Cell. Neurosci. 28, 375-389. doi: 10.1016/j.mcn.2004.10.009

Cooper, A., Grigoryan, G., Guy-David, L., Tsoory, M. M., Chen, A., and Reuveny, E. (2012). Trisomy of the $\mathrm{G}$ protein-coupled $\mathrm{K}^{+}$channel gene, Kcnj6, affects reward mechanisms, cognitive functions, and synaptic plasticity in mice. Proc. Natl. Acad. Sci. U.S.A. 109, 2642-2647. doi: 10.1073/pnas.1109099109

Cruz, H. G., Ivanova, T., Lunn, M. L., Stoffel, M., Slesinger, P. A., and Luscher, C. (2004). Bi-directional effects of GABA(B) receptor agonists on the mesolimbic dopamine system. Nat. Neurosci. 7, 153-159. doi: 10.1038/nn1181

Dopico, A. M., Anantharam, V., and Treistman, S. N. (1998). Ethanol increases the activity of $\mathrm{Ca}^{2+}$-dependent $\mathrm{K}^{+}$(mslo) channels: functional interaction with cytosolic $\mathrm{Ca}^{2+}$. J. Pharmacol. Exp. Ther. 284, 258-268.

Ehlers, C. L., Walter, N. A., Dick, D. M., Buck, K. J., and Crabbe, J. C. (2010). A comparison of selected quantitative trait loci associated with alcohol use phenotypes in humans and mouse models. Addict. Biol. 15, 185-199. doi: 10.1111/j.1369-1600.2009.00195.x

Ehrengruber, M. U., Doupnik, C. A., Xu, Y., Garvey, J., Jasek, M. C., Lester, H. A., et al. (1997). Activation of heteromeric $G$ protein-gated inward rectifier $\mathrm{K}^{+}$channels overexpressed by adenovirus gene transfer inhibits the excitability of hippocampal neurons. Proc. Natl. Acad. Sci. U.S.A. 94, 7070-7075. doi: 10.1073/pnas.94.13.7070

Engel, S. R., and Allan, A. M. (1999). 5- $\mathrm{HT}_{3}$ receptor over-expression enhances ethanol sensitivity in mice. Psychopharmacology 144, 411-415. doi: $10.1007 / \mathrm{s} 002130051025$

Federici, M., Nistico, R., Giustizieri, M., Bernardi, G., and Mercuri, N. B. (2009). Ethanol enhances GABAB-mediated inhibitory postsynaptic transmission on rat midbrain dopaminergic neurons by facilitating GIRK currents. Eur. J. Neurosci. 29, 1369-1377. doi: 10.1111/j.1460-9568. 2009.06700.x

Finley, M., Arrabit, C., Fowler, C., Suen, K. F., and Slesinger, P. A. (2004). $\beta L-\beta M$ loop in the $\mathrm{C}$-terminal domain of $\mathrm{G}$ protein-activated inwardly rectifying $\mathrm{K}^{+}$ channels is important for G $\beta \gamma$ subunit activation. J. Physiol. 555, 643-657. doi: 10.1113/jphysiol.2003.056101

Hamasaki, R., Shirasaki, T., Soeda, F., and Takahama, K. (2013). Tipepidine activates VTA dopamine neuron via inhibiting dopamine D receptormediated inward rectifying K current. Neuroscience 252C, 24-34. doi: 10.1016/j.neuroscience.2013.07.044

Harris, R. A., Trudell, J. R., and Mihic, S. J. (2008). Ethanol's molecular targets. Sci. Signal. 1, re7. doi: 10.1126/scisignal.128re7

He, C., Zhang, H., Mirshahi, T., and Logothetis, D. E. (1999). Identification of a potassium channel site that interacts with $G$ protein $\beta \gamma$ subunits to mediate agonist-induced signaling. J. Biol. Chem. 274, 12517-12524. doi: 10.1074/jbc.274.18.12517

Heusler, P., Bruins Slot, L., Tourette, A., Tardif, S., and Cussac, D. (2011). The clozapine metabolite $\mathrm{N}$-desmethylclozapine displays variable activity in diverse functional assays at human dopamine $\mathrm{D}(2)$ and serotonin 5-HT(1)A receptors. Eur. J. Pharmacol. 669, 51-58. doi: 10.1016/j.ejphar.2011.07.031

Hill, K. G., Alva, H., Blednov, Y. A., and Cunningham, C. L. (2003). Reduced ethanol-induced conditioned taste aversion and conditioned place preference in GIRK2 null mutant mice. Psychopharmacology 169, 108-114. doi: 10.1007/s00213-003-1472-4

Ho, I. H., and Murrell-Lagnado, R. D. (1999). Molecular mechanism for sodiumdependent activation of $\mathrm{G}$ protein-gated $\mathrm{K}^{+}$channels. J. Physiol. 520(Pt 3), 645-651. doi: 10.1111/j.1469-7793.1999.00645.x
Hodge, C. W., Mehmert, K. K., Kelley, S. P., McMahon, T., Haywood, A., Olive, M. F., et al. (1999). Supersensitivity to allosteric GABA(A) receptor modulators and alcohol in mice lacking PKCepsilon. Nat. Neurosci. 2, 997-1002. doi: 10.1038/14795

Howard, R. J., Murail, S., Ondricek, K. E., Corringer, P. J., Lindahl, E., Trudell, J. R., et al. (2011a). Structural basis for alcohol modulation of a pentameric ligand-gated ion channel. Proc. Natl. Acad. Sci. U.S.A. 108, 12149-12154. doi: 10.1073/pnas.1104480108

Howard, R. J., Slesinger, P. A., Davies, D. L., Das, J., Trudell, J. R., and Harris, R. A. (2011b). Alcohol-binding sites in distinct brain proteins: the quest for atomic level resolution. Alcohol. Clin. Exp. Res. 35, 1561-1573. doi: 10.1111/j.15300277.2011.01502.x

Huang, C. L., Feng, S., and Hilgemann, D. W. (1998). Direct activation of inward rectifier potassium channels by $\mathrm{PIP}_{2}$ and its stabilization by G $\beta \gamma$. Nature 391, 803-806. doi: 10.1038/35882

Huang, C. L., Jan, Y. N., and Jan, L. Y. (1997). Binding of the G protein $\beta \gamma$ subunit to multiple regions of $\mathrm{G}$ protein-gated inward-rectifying $\mathrm{K}^{+}$channels. FEBS Lett. 405, 291-298. doi: 10.1016/S0014-5793(97)00197-X

Huang, C. L., Slesinger, P. A., Casey, P. J., Jan, Y. N., and Jan, L. Y. (1995). Evidence that direct binding of G $\beta \gamma$ to the GIRK1 G protein-gated inwardly rectifying $\mathrm{K}^{+}$channel is important for channel activation. Neuron 15, 1133-1143. doi: 10.1016/0896-6273(95)90101-9

Ikeda, K., Kobayashi, T., Kumanishi, T., Yano, R., Sora, I., and Niki, H. (2002). Molecular mechanisms of analgesia induced by opioids and ethanol: is the GIRK channel one of the keys? Neurosci. Res. 44, 121-131. doi: 10.1016/S01680102(02)00094-9

Inanobe, A., Horio, Y., Fujita, A., Tanemoto, M., Hibino, H., Inageda, K., et al. (1999). Molecular cloning and characterization of a novel splicing variant of the Kir3.2 subunit predominantly expressed in mouse testis. J. Physiol. 521(Pt 1), 19-30. doi: 10.1111/j.1469-7793.1999.00019.x

Inanobe, A., Nakagawa, A., Matsuura, T., and Kurachi, Y. (2010). A structural determinant for the control of $\mathrm{PIP}_{2}$ sensitivity in $\mathrm{G}$ protein-gated inward rectifier $\mathrm{K}^{+}$channels. J. Biol. Chem. 285, 38517-38523. doi: 10.1074/jbc.M110. 161703

Ivanina, T., Rishal, I., Varon, D., Mullner, C., Frohnwieser-Steinecke, B., Schreibmayer, W., et al. (2003). Mapping the G $\beta \gamma$-binding sites in GIRK1 and GIRK2 subunits of the G protein-activated $\mathrm{K}^{+}$channel. J. Biol. Chem. 278, 29174-29183. doi: 10.1074/jbc.M304518200

Ivanina, T., Varon, D., Peleg, S., Rishal, I., Porozov, Y., Dessauer, C. W., et al. (2004). Galphail and Galphai3 differentially interact with, and regulate, the $\mathrm{G}$ protein-activated $\mathrm{K}^{+}$channel. J. Biol. Chem. 279, 17260-17268. doi: 10.1074/jbc.M313425200

Jelacic, T. M., Kennedy, M. E., Wickman, K., and Clapham, D. E. (2000). Functional and biochemical evidence for G-protein-gated inwardly rectifying $\mathrm{K}^{+}$(GIRK) channels composed of GIRK2 and GIRK3. J. Biol. Chem. 275, 36211-36216. doi: 10.1074/jbc.M007087200

Kaufmann, K., Romaine, I., Days, E., Pascual, C., Malik, A., Yang, L., et al. (2013). ML297 (VU0456810), the first potent and selective activator of the GIRK potassium channel, displays antiepileptic properties in mice. ACS Chem. Neurosci. 4, 1278-1286. doi: 10.1021/cn400062a

Kobayashi, T., Ikeda, K., Kojima, H., Niki, H., Yano, R., Yoshioka, T., et al. (1999). Ethanol opens G-protein-activated inwardly rectifying $\mathrm{K}^{+}$channels. Nat. Neurosci. 2, 1091-1097. doi: 10.1038/16019

Kobayashi, T., Ikeda, K., and Kumanishi, T. (2000). Inhibition by various antipsychotic drugs of the G-protein-activated inwardly rectifying $\mathrm{K}^{+}(\mathrm{GIRK})$ channels expressed in Xenopus oocytes. Br. J. Pharmacol. 129, 1716-1722. doi: 10.1038/sj.bjp.0703224

Kobayashi, T., Washiyama, K., and Ikeda, K. (2004). Inhibition of G protein-activated inwardly rectifying $\mathrm{K}^{+}$channels by various antidepressant drugs. Neuropsychopharmacology 29, 1841-1851. doi: 10.1038/sj.npp. 1300484

Kobayashi, T., Washiyama, K., and Ikeda, K. (2011). Inhibition of G proteinactivated inwardly rectifying $\mathrm{K}^{+}$channels by different classes of antidepressants. PLoS ONE 6:e28208. doi: 10.1371/journal.pone.0028208

Kozell, L. B., Walter, N. A., Milner, L. C., Wickman, K., and Buck, K. J. (2009). Mapping a barbiturate withdrawal locus to a $0.44 \mathrm{Mb}$ interval and analysis of a novel null mutant identify a role for Kcnj9 (GIRK3) in withdrawal from pentobarbital, zolpidem, and ethanol. J. Neurosci. 29, 11662-11673. doi: 10.1523/JNEUROSCI.1413-09.2009 
Kruse, S. W., Zhao, R., Smith, D. P., and Jones, D. N. (2003). Structure of a specific alcohol-binding site defined by the odorant binding protein LUSH from Drosophila melanogaster. Nat. Struct. Biol. 10, 694-700. doi: 10.1038/nsb960

Kunkel, M. T., and Peralta, E. G. (1995). Identification of domains conferring G protein regulation on inward rectifier potassium channels. Cell 83, 443-449. doi: 10.1016/0092-8674(95)90122-1

Labouebe, G., Lomazzi, M., Cruz, H. G., Creton, C., Lujan, R., Li, M., et al. (2007). RGS2 modulates coupling between GABAB receptors and GIRK channels in dopamine neurons of the ventral tegmental area. Nat. Neurosci. 10, 1559-1568. doi: $10.1038 / \mathrm{nn} 2006$

Lesage, F., Guillemare, E., Fink, M., Duprat, F., Heurteaux, C., Fosset, M., et al. (1995). Molecular properties of neuronal G-protein-activated inwardly rectifying $\mathrm{K}^{+}$channels. J. Biol. Chem. 270, 28660-28667. doi: 10.1074/jbc.270.48. 28660

Lewis, M. J., Johnson, D. F., Waldman, D., Leibowitz, S. F., and Hoebel, B. G. (2004). Galanin microinjection in the third ventricle increases voluntary ethanol intake. Alcohol. Clin. Exp. Res. 28, 1822-1828. doi: 10.1097/01.ALC. 0000148099.12344.C8

Lewohl, J. M., Wilson, W. R., Mayfield, R. D., Brozowski, S. J., Morrisett, R. A., and Harris, R. A. (1999). G-protein-coupled inwardly rectifying potassium channels are targets of alcohol action. Nat. Neurosci. 2, 1084-1090. doi: 10.1038/16012

Li, J., Nie, H., Bian, W., Dave, V., Janak, P. H., and Ye, J. H. (2012). Microinjection of glycine into the ventral tegmental area selectively decreases ethanol consumption. J. Pharmacol. Exp. Ther. 341, 196-204. doi: 10.1124/jpet.111.190058

Logothetis, D. E., Kurachi, Y., Galper, J., Neer, E. J., and Clapham, D. E. (1987). The $\beta \gamma$ subunits of GTP-binding proteins activate the muscarinic $\mathrm{K}^{+}$channel in heart. Nature 325, 321-326. doi: 10.1038/325321a0

Lovinger, D. M., White, G., and Weight, F. F. (1989). Ethanol inhibits NMDAactivated ion current in hippocampal neurons. Science 243, 1721-1724. doi: $10.1126 /$ science. 2467382

Lujan, R., Maylie, J., and Adelman, J. P. (2009). New sites of action for GIRK and SK channels. Nat. Rev. Neurosci. 10, 475-480. doi: 10.1038/nrn2668

Lunn, M. L., Nassirpour, R., Arrabit, C., Tan, J., McLeod, I., Arias, C. M., et al. (2007). A unique sorting nexin regulates trafficking of potassium channels via a PDZ domain interaction. Nat. Neurosci. 10, 1249-1259. doi: 10.1038/nn1953

Luscher, C., Jan, L. Y., Stoffel, M., Malenka, R. C., and Nicoll, R. A. (1997). G protein-coupled inwardly rectifying $\mathrm{K}^{+}$channels (GIRKs) mediate postsynaptic but not presynaptic transmitter actions in hippocampal neurons. Neuron 19, 687-695. doi: 10.1016/S0896-6273(00)80381-5

Luscher, C., and Slesinger, P. A. (2010). Emerging roles for G protein-gated inwardly rectifying potassium (GIRK) channels in health and disease. Nat. Rev. Neurosci. 11, 301-315. doi: 10.1038/nrn2834

Mahajan, R., Ha, J., Zhang, M., Kawano, T., Kozasa, T., and Logothetis, D. E. (2013). A computational model predicts that Gbetagamma acts at a cleft between channel subunits to activate GIRK1 channels. Sci. Signal. 6, ra69. doi: 10.1126/scisignal.2004075

Marinelli, P. W., Funk, D., Juzytsch, W., and Le, A. D. (2010). Opioid receptors in the basolateral amygdala but not dorsal hippocampus mediate context-induced alcohol seeking. Behav. Brain Res. 211, 58-63. doi: 10.1016/j.bbr.2010.03.008

Mascia, M. P., Trudell, J. R., and Harris, R. A. (2000). Specific binding sites for alcohols and anesthetics on ligand-gated ion channels. Proc. Natl. Acad. Sci. U.S.A. 97, 9305-9310. doi: 10.1073/pnas.160128797

Mase, Y., Yokogawa, M., Osawa, M., and Shimada, I. (2012). Structural basis for modulation of gating property of $\mathrm{G}$ protein-gated inwardly rectifying potassium ion channel (GIRK) by i/o-family G protein alpha subunit (Galphai/o). J. Biol. Chem. 287, 19537-19549. doi: 10.1074/jbc.M112.353888

Mazarati, A., Lundstrom, L., Sollenberg, U., Shin, D., Langel, U., and Sankar, R. (2006). Regulation of kindling epileptogenesis by hippocampal galanin type 1 and type 2 receptors: the effects of subtype-selective agonists and the role of G-protein-mediated signaling. J. Pharmacol. Exp. Ther. 318, 700-708. doi: 10.1124/jpet.106.104703

McBride, W. J., Lovinger, D. M., Machu, T., Thielen, R. J., Rodd, Z. A., Murphy, J. M., et al. (2004). Serotonin-3 receptors in the actions of alcohol, alcohol reinforcement, and alcoholism. Alcohol. Clin. Exp. Res. 28, 257-267. doi: 10.1097/01.ALC.0000113419.99915.DA

Michaeli, A., and Yaka, R. (2010). Dopamine inhibits GABA(A) currents in ventral tegmental area dopamine neurons via activation of presynaptic G-protein coupled inwardly-rectifying potassium channels. Neuroscience 165, 1159-1169. doi: 10.1016/j.neuroscience.2009.11.045
Mihic, S. J., Whiting, P. J., and Harris, R. A. (1994). Anaesthetic concentrations of alcohols potentiate GABAA receptor-mediated currents: lack of subunit specificity. Eur. J. Pharmacol. 15, 268, 209-214. doi: 10.1016/0922-4106(94)90190-2

Mihic, S. J., Ye, Q., Wick, M. J., Koltchine, V. V., Krasowski, M. D., Finn, S. E., et al. (1997). Sites of alcohol and volatile anaesthetic action on GABA(A) and glycine receptors. Nature 389, 385-389. doi: 10.1038/38738

Morgan, A. D., Carroll, M. E., Loth, A. K., Stoffel, M., and Wickman, K. (2003). Decreased cocaine self-administration in Kir3 potassium channel subunit knockout mice. Neuropsychopharmacology 28, 932-938. doi: 10.1038/sj.npp.1300100

Nam, H. W., Hinton, D. J., Kang, N. Y., Kim, T., Lee, M. R., Oliveros, A., et al. (2013). Adenosine transporter ENT1 regulates the acquisition of goal-directed behavior and ethanol drinking through $\mathrm{A} 2 \mathrm{~A}$ receptor in the dorsomedial striatum. J. Neurosci. 33, 4329-4338. doi: 10.1523/JNEUROSCI.3094-12.2013

Newton, P. M., and Ron, D. (2007). Protein kinase C and alcohol addiction. Pharmacol. Res. 55, 570-577. doi: 10.1016/j.phrs.2007.04.008

Padgett, C. L., Lalive, A. L., Tan, K. R., Terunuma, M., Munoz, M. B., Pangalos, M. N., et al. (2012). Methamphetamine-evoked depression of GABA(B) receptor signaling in GABA neurons of the VTA. Neuron 73, 978-989. doi: 10.1016/j.neuron.2011.12.031

Pastor, R., Reed, C., Burkhart-Kasch, S., Li, N., Sharpe, A. L., Coste, S. C., et al. (2011). Ethanol concentration-dependent effects and the role of stress on ethanol drinking in corticotropin-releasing factor type 1 and double type 1 and 2 receptor knockout mice. Psychopharmacology 218, 169-177. doi: 10.1007/s00213-011-2284-6

Patil, N., Cox, D. R., Bhat, D., Faham, M., Myers, R. M., and Peterson, A. S. (1995). A potassium channel mutation in weaver mice implicates membrane excitability in granule cell differentiation. Nat. Genet. 11, 126-129. doi: 10.1038/ng1095-126

Pegan, S., Arrabit, C., Slesinger, P. A., and Choe, S. (2006). Andersen's syndrome mutation effects on the structure and assembly of the cytoplasmic domains of Kir2.1. Biochemistry 45, 8599-8606. doi: 10.1021/bi060653d

Pegan, S., Arrabit, C., Zhou, W., Kwiatkowski, W., Collins, A., Slesinger, P. A., et al. (2005). Cytoplasmic domain structures of Kir2.1 and Kir3.1 show sites for modulating gating and rectification. Nat. Neurosci. 8, 279-287. doi: 10.1038/nn1411

Pei, Q., Lewis, L., Grahame-Smith, D. G., and Zetterstrom, T. S. (1999). Alteration in expression of $\mathrm{G}$-protein-activated inward rectifier $\mathrm{K}^{+}$-channel subunits GIRK1 and GIRK2 in the rat brain following electroconvulsive shock. Neuroscience 90, 621-627. doi: 10.1016/S0306-4522(98)00453-9

Penn, R. D., and Kroin, J. S. (1985). Continuous intrathecal baclofen for severe spasticity. Lancet 326, 125-127. doi: 10.1016/S0140-6736(85)90228-4

Petit-Jacques, J., Sui, J. L., and Logothetis, D. E. (1999). Synergistic activation of G protein-gated inwardly rectifying potassium channels by the betagamma subunits of $\mathrm{G}$ proteins and $\mathrm{Na}^{+}$and $\mathrm{Mg}^{2+}$ ions. J. Gen. Physiol. 114, 673-684. doi: 10.1085/jgp.114.5.673

Plapp, B. V. (2010). Conformational changes and catalysis by alcohol dehydrogenase. Arch. Biochem. Biophys. 493, 3-12. doi: 10.1016/j.abb.2009.07.001

Reuveny, E., Slesinger, P. A., Inglese, J., Morales, J. M., Iniguez-Lluhi, J. A., Lefkowitz, R. J., et al. (1994). Activation of the cloned muscarinic potassium channel by $G$ protein $\beta \gamma$ subunits. Nature 370, 143-146. doi: 10.1038/370143a0

Rodd, Z. A., Bell, R. L., Oster, S. M., Toalston, J. E., Pommer, T. J., McBride, W. J., et al. (2010). Serotonin-3 receptors in the posterior ventral tegmental area regulate ethanol self-administration of alcohol-preferring $(\mathrm{P})$ rats. Alcohol 44, 245-255. doi: 10.1016/j.alcohol.2010.01.002

Rubinstein, M., Peleg, S., Berlin, S., Brass, D., and Dascal, N. (2007). Galphai3 primes the $\mathrm{G}$ protein-activated $\mathrm{K}^{+}$channels for activation by coexpressed Gbetagamma in intact Xenopus oocytes. J. Physiol. 581, 17-32. doi: 10.1113/jphysiol.2006.125864

Sauguet, L., Howard, R. J., Malherbe, L., Lee, U. S., Corringer, P. J., Harris, R. A., et al. (2013). Structural basis for potentiation by alcohols and anaesthetics in a ligand-gated ion channel. Nat. Commun. 4, 1697. doi: 10.1038/ncomms2682

Scanziani, M. (2000). GABA spillover activates postsynaptic GABA(B) receptors to control rhythmic hippocampal activity. Neuron 25, 673-681. doi: 10.1016/S0896-6273(00)81069-7

Schein, J. C., Wang, J. K., and Roffler-Tarlov, S. K. (2005). The effect of GIRK2(wv) on neurite growth, protein expression, and viability in the CNSderived neuronal cell line, CATH.A-differentiated. Neuroscience 134, 21-32. doi: 10.1016/j.neuroscience.2005.03.043

Siarey, R. J., Carlson, E. J., Epstein, C. J., Balbo, A., Rapoport, S. I., and Galdzicki, Z. (1999). Increased synaptic depression in the Ts65Dn mouse, a model for 
mental retardation in Down syndrome. Neuropharmacology 38, 1917-1920. doi: 10.1016/S0028-3908(99)00083-0

Signorini, S., Liao, Y. J., Duncan, S. A., Jan, L. Y., and Stoffel, M. (1997). Normal cerebellar development but susceptibility to seizures in mice lacking $\mathrm{G}$ proteincoupled, inwardly rectifying $\mathrm{K}^{+}$channel GIRK2. Proc. Natl. Acad. Sci. U.S.A. 94 923-927. doi: 10.1073/pnas.94.3.923

Silberman, Y., Bajo, M., Chappell, A. M., Christian, D. T., Cruz, M., Diaz, M. R., et al. (2009). Neurobiological mechanisms contributing to alcohol-stressanxiety interactions. Alcohol 43, 509-519. doi: 10.1016/j.alcohol.2009.01.002

Slesinger, P. A. (2001). Ion selectivity filter regulates local anesthetic inhibition of G-protein-gated inwardly rectifying $\mathrm{K}^{+}$channels. Biophys. J. 80, 707-718. doi: 10.1016/S0006-3495(01)76050-X

Slesinger, P. A., Patil, N., Liao, Y. J., Jan, Y. N., Jan, L. Y., and Cox, D. R. (1996). Functional effects of the mouse weaver mutation on $G$ protein-gated inwardly rectifying $\mathrm{K}^{+}$channels. Neuron 16, 321-331. doi: 10.1016/S08966273(00)80050-1

Styer, A. M., Mirshahi, U. L., Wang, C., Girard, L., Jin, T., Logothetis, D. E., et al. (2010). G protein $\beta \gamma$ gating confers volatile anesthetic inhibition to Kir3 channels. J. Biol. Chem. 285, 41290-41299. doi: 10.1074/jbc.M110.178541

Sung, K. W., Engel, S. R., Allan, A. M., and Lovinger, D. M. (2000). 5-HT 3 receptor function and potentiation by alcohols in frontal cortex neurons from transgenic mice overexpressing the receptor. Neuropharmacology 39, 2346-2351. doi: 10.1016/S0028-3908(00)00064-2

Theile, J. W., Morikawa, H., Gonzales, R. A., and Morrisett, R. A. (2011). GABAergic transmission modulates ethanol excitation of ventral tegmental area dopamine neurons. Neuroscience 172, 94-103. doi: 10.1016/j.neuroscience.2010.10.046

Tong, W., and Sun, G. Y. (1996). Effects of ethanol on phosphorylation of lipids in rat synaptic plasma membranes. Alcohol. Clin. Exp. Res. 20, 1335-1339. doi: 10.1111/j.1530-0277.1996.tb01131.x

Vendruscolo, L. F., Barbier, E., Schlosburg, J. E., Misra, K. K., Whitfield, T. W. Jr., Logrip, M. L., et al. (2012). Corticosteroid-dependent plasticity mediates compulsive alcohol drinking in rats. J. Neurosci. 32, 7563-7571. doi 10.1523/JNEUROSCI.0069-12.2012

Walker, B. M., Zorrilla, E. P., and Koob, G. F. (2011). Systemic к-opioid receptor antagonism by nor-binaltorphimine reduces dependence-induced excessive alcohol self-administration in rats. Addict. Biol. 16, 116-119. doi: 10.1111/j.1369-1600.2010.00226.x

Whorton, M. R., and MacKinnon, R. (2011). Crystal structure of the mammalian GIRK $2 \mathrm{~K}^{+}$channel and gating regulation by $\mathrm{G}$ proteins, $\mathrm{PIP}_{2}$, and sodium. Cell 147, 199-208. doi: 10.1016/j.cell.2011.07.046

Whorton, M. R., and MacKinnon, R. (2013). X-ray structure of the mammalian GIRK2-betagamma G-protein complex. Nature 498, 190-197. doi: 10.1038 /nature 12241
Wickman, K. D., Iniguez-Lluhl, J. A., Davenport, P. A., Taussig, R., Krapivinsky, G. B., Linder, M. E., et al. (1994). Recombinant G-protein $\beta \gamma$-subunits activate the muscarinic-gated atrial potassium channel. Nature 368, 255-257. doi: $10.1038 / 368255 \mathrm{a} 0$

Wickman, K., Karschin, C., Karschin, A., Picciotto, M. R., and Clapham, D. E. (2000). Brain localization and behavioral impact of the G-protein-gated $\mathrm{K}^{+}$ channel subunit GIRK4. J. Neurosci. 20, 5608-5615.

Wiser, O., Qian, X., Ehlers, M., Ja, W. W., Roberts, R. W., Reuveny, E., et al. (2006). Modulation of basal and receptor-induced GIRK potassium channel activity and neuronal excitability by the mammalian PINS homolog LGN. Neuron 50, 561-573. doi: 10.1016/j.neuron.2006.03.046

Xiao, J., Zhen, X. G., and Yang, J. (2003). Localization of $\mathrm{PIP}_{2}$ activation gate in inward rectifier $\mathrm{K}^{+}$channels. Nat. Neurosci. 6, 811-818. doi: 10.1038/nn1090

Yamakura, T., Lewohl, J. M., and Harris, R. A. (2001). Differential effects of general anesthetics on $\mathrm{G}$ protein-coupled inwardly rectifying and other potassium channels. Anesthesiology 95, 144-153. doi: 10.1097/00000542-200107000-00025

Zhang, H., He, C., Yan, X., Mirshahi, T., and Logothetis, D. E. (1999). Activation of inwardly rectifying $\mathrm{K}^{+}$channels by distinct PtdIns $(4,5) \mathrm{P} 2$ interactions. Nat. Cell Biol. 1, 183-188. doi: 10.1038/11103

Zhou, W., Arrabit, C., Choe, S., and Slesinger, P. A. (2001). Mechanism underlying bupivacaine inhibition of $\mathrm{G}$ protein-gated inwardly rectifying $\mathrm{K}^{+}$channels. Proc. Natl. Acad. Sci. U.S.A. 98, 6482-6487. doi: 10.1073/pnas.111447798

Zorrilla, E. P., and Koob, G. F. (2010). Progress in corticotropin-releasing factor-1 antagonist development. Drug Discov. Today 15, 371-383. doi: 10.1016/j.drudis.2010.02.011

Conflict of Interest Statement: The authors declare that the research was conducted in the absence of any commercial or financial relationships that could be construed as a potential conflict of interest.

Received: 04 December 2013; accepted: 07 February 2014; published online: 25 February 2014.

Citation: Bodhinathan K and Slesinger PA (2014) Alcohol modulation of G-proteingated inwardly rectifying potassium channels: from binding to therapeutics. Front Physiol. 5:76. doi: 10.3389/fphys.2014.00076

This article was submitted to Membrane Physiology and Membrane Biophysics, a section of the journal Frontiers in Physiology.

Copyright (c) 2014 Bodhinathan and Slesinger. This is an open-access article distributed under the terms of the Creative Commons Attribution License (CC BY). The use, distribution or reproduction in other forums is permitted, provided the original author(s) or licensor are credited and that the original publication in this journal is cited, in accordance with accepted academic practice. No use, distribution or reproduction is permitted which does not comply with these terms. 